\title{
Ressignificando o conceito de alfabetização: uma contribuição para o ensino da língua materna na contemporaneidade
}

\author{
Maria de Fátima Ramos de Andrade* \\ Ana Sílvia Moço Aparício**
}

\begin{abstract}
Resumo
O presente texto se propõe a discutir a ampliação do conceito de alfabetização, considerando a expansão da escrita no contexto cultural da atualidade. Para isso, apresentamos inicialmente alguns aspectos relevantes da história da escrita, procurando destacar os diferentes sistemas de representação construídos pelo homem. Na sequência, discutimos o conceito de alfabetização, na perspectiva da escrita alfabética, ainda bastante recorrente nas orientações e práticas de ensino e aprendizagem da língua escrita. Por fim, discutimos as escritas contemporâneas e suas influências na cultura e no pensamento da sociedade atual e o conceito de alfabetização semiótica.
\end{abstract}

Palavras-chave: Alfabetização semiótica. Processos comunicacionais. Escritas contemporâneas.

\section{Introdução}

Com a expansão dos processos comunicativos, novas formas de interação, de percepção, de visibilidade, assim como novas redes de transmissão de informações foram se constituindo. A presença das tecnologias, em nosso cotidiano, gerou transformações nos processos comunicacionais, na forma de aprender, na prática de leitura e também de expressão escrita. Hoje, percebemos diferentes formas de convivência com os aparatos tecnológicos. Apesar de muitos ainda não utilizarem o livro, usufruem das imagens produzidas pelos aparelhos eletrônicos. Esse estado de complexidade e inovação crescentes vem exigindo reflexão e análise.

* Universidade Presbiteriana Mackenzie (UPM).

** Universidade Municipal de São Caetano do Sul (USCS). 
A nossa convivência com os meios, apesar de "pacífica", tem sido marcada pelo desconhecimento que temos de sua mediação. O presente texto se propõe a ressignificar o conceito de alfabetização, considerando a expansão da escrita no contexto cultural atual.

\section{Um pouco da história: a construção do sistema de representação alfabético}

Dificílimo acto é o de escrever, responsabilidade das maiores, basta pensar no extenuante trabalho que será dispor por ordem temporal os acontecimentos, primeiro este, depois aquele, ou, se tal mais convém às necessidades do efeito, o sucesso de hoje posto antes do episódio de ontem, e outras não menos arriscadas acrobacias, o passado como se estivesse sido agora, o presente como um contínuo sem princípio nem fim, mas, por muito que se esforcem os autores, uma habilidade não podem cometer, pôr por escrito, no mesmo tempo, dois casos no mesmo tempo acontecidos. Há quem julgue que a dificuldade fica resolvida dividindo a página em duas colunas, lado a lado, mas o ardil é ingénuo, porque primeiro se escreveu uma e só depois a outra, sem esquecer que o leitor terá de ler primeiro esta e depois aquela, ou vice-versa, quem está bem são os cantores de ópera, cada um com sua parte nos concertantes, três quatro cinco seis entre tenores baixos sopranos e barítonos, todos a cantar palavras diferentes, por exemplo, o cínico escarnecendo, a ingénua suplicando, o galã tardo em acudir, ao espectador o que lhe interessa é a música, já ao leitor não é assim, quer tudo explicado, sílaba por sílaba e uma após outra, como aqui se mostram. (SARAMAGO, 1980, p. 26).

Nas primeiras páginas do livro A jangada de pedra, o personagem-narrador de Saramago confessa a sua dificuldade em contar os fatos e as histórias que motivaram a narrativa que inicia. Saramago, por meio de sua personagem, discute a quase impossibilidade de dispor, por ordem temporal, os acontecimentos: primeiro um, depois o outro. Um fato colocado antes de outro. O uso da pontuação, no texto, é exemplar para a apresentação dessa dificuldade. A narrativa escrita tende a ser linear por essas dificuldades apontadas tão lucidamente pela personagem de Saramago. Como narrar então a história da escrita?

Ao situarmos determinado sistema - a escrita - temos de considerar como ele se constituiu, ou seja, que fatos, situações, acontecimentos no contexto histórico permitiram a sua elaboração. Poderíamos narrar essa história desde seus primórdios, ou seja, desde a pré-história, quando o homem já procurava estratégias para registrar suas intenções, seus pensamentos. 
Vários dispositivos de registro - uma vara entalhada, fileiras de seixos, calendários de contagem de inverno, etc. - foram usados por várias sociedades para memorizar fatos, situações. No entanto, a escrita é mais do que um auxílio mnemônico: "um registro escrito, no sentido de uma escrita genuína, tal como entendido aqui, não consiste em meros desenhos, em representações de coisas, é a representação de uma elocução, de palavras que alguém diz ou se imagina que diz" (ONG, 1998, p. 99).

A escrita entendida como qualquer marca semiótica, visível, perceptível, banaliza seu significado. Segundo Ong (1998), a escrita é a tecnologia que moldou e capacitou a atividade intelectual do homem moderno. Dizer que é uma tecnologia é trabalhar com a ideia de que ela se constituiu a partir de regras conscientemente pensadas/planejadas e inter-relacionadas: um sistema convencional.

A escrita - tecnologia que, interiorizada, potencializou nossa consciência ocorreu tardiamente na história da humanidade. O homo sapiens está no planeta talvez há cerca de 50 mil anos; o primeiro registro escrito que conhecemos foi desenvolvido entre os sumérios por volta do ano 3500 a C. (ONG, 1998).

Como lembrar determinados fatos por muito tempo? Como registrar que um determinado número de bois pertencia a uma determinada família? Um sinal mnemônico poderia ser usado para dizer ao leitor quantos bois estavam em jogo ou quem era seu dono. $\mathrm{O}$ criador das primeiras tabuletas escritas deve ter percebido as vantagens que essas peças de argila propiciavam: não era mais preciso memorizar todas as informações; a presença de quem fazia o registro não era mais necessária. Logo, uma informação, um número, uma notícia poderiam ser obtidos mesmo sem que o informante estivesse presente (MANGUEL, 2002).

Contudo, vale ressaltar que "o registro escrito é mais do que um auxílio mnemônico. Até mesmo quando é pictográfico, um registro escrito é mais do que desenhos. Os desenhos representam objetos" (ONG, 1998, p. 99). Por exemplo, o desenho de um homem, uma casa ou uma árvore, pouco diz; já os sistemas de convenções/códigos são mais que figuras. Para Ong (1998), os sistemas de escrita têm antecedentes complexos, pois direta ou indiretamente remontam a alguma espécie de escrita pictórica ou, de uma forma mais elementar, ao uso de sinais.

Sem ter a intenção de seguir uma linha cronológica, de maneira geral, pode-se caracterizar a história da escrita em três fases distintas: a pictórica, a ideográfica e a alfabética. Entretanto, é importante que se diga que qualquer tipo de divisão deve ser vista com cautela, pois "coexistem em quase todos os sistemas antigos 
elementos ideográficos e elementos fonéticos" (HIGOUNET, 2003, p. 58). Na verdade, qualquer possível classificação de um sistema semiótico acaba sendo falha, pois dificilmente dá conta da complexidade do fenômeno semiótico: as conexões estabelecidas na construção de novos processos comunicacionais. ${ }^{1}$

A fase "pictográfica se distingue pela escrita através de desenhos ou pictogramas. Estes aparecem em inscrições antigas, mas podem ser vistos de maneira mais elaborada nos cantos Ojibwa da América do Norte, na escrita asteca [...] e, mais recentemente, nas histórias em quadrinhos" (CAGLIARI, 1990, p. 106). Os pictogramas não representam os sons, mas a imagem do que se pretende representar.

A fase ideográfica se caracteriza pela escrita através de desenhos chamados ideogramas. O ideograma é uma espécie de pictograma no qual o significado é um conceito que resulta da combinação de figuras representadas pelo desenho. O desenho de uma árvore, na fase pictográfica, representa uma árvore. Já na fase ideográfica, um desenho de duas árvores não representa "duas árvores", mas a palavra floresta, no caso da escrita chinesa, por exemplo. Dessa forma, todos os sistemas pictográficos, como no caso dos ideogramas chineses, exigem uma quantidade enorme de símbolos (ONG, 1998).

Os caracteres do sistema ideográfico também podem ser usados para representar sílabas, adquirindo, assim, um caráter fonográfico. Com isso, esses sistemas de escrita são chamados silábicos, pois visam representar sílabas. Para Havelock (1994), o sistema silábico partiu do princípio de que cada um dos sons efetivamente pronunciáveis em separado, numa língua dada, poderia ser simbolizado. A escrita egípcia foi um dos mais importantes sistemas de escrita do mundo antigo. "Sob sua forma mais característica e mais antiga, é chamada escrita hieroglífica. Os hieróglifos eram sinais gravados (do grego hieros, "sagrado", e glyphein, "gravar") que os egípcios consideravam ser a fala dos deuses" (HIGOUNET, 2003, p. 37).

Contudo, essas escritas são, incorreta e frequentemente, classificadas como ideográficas. "Embora possam muito bem ter sido ideográficas na origem, os

1 É importante ressaltar que determinadas escritas não passaram pelas transformações dessas três fases. Muitos sistemas de escrita são híbridos, ou seja, fazem uso de dois ou mais princípios. Por exemplo, o sistema japonês é híbrido, pois, além de usar caracteres chineses (ideogramas), ele também é silábico. Segundo Ong (1998), a tendência que têm determinados sistemas de escrita em começar com pictogramas e se desenvolver para ideogramas e rébus, talvez a maioria dos sistemas de escrita que não o alfabeto seja até certo ponto híbrido. E até mesmo a escrita alfabética se torna híbrida quando escreve 1 em vez de um. 
mais antigos exemplos conhecidos só em parte são ideográficos, apresentando também um elemento fonético, e combinando-se as duas formas de vários modos" (DIRINGER, 1985, p. 25). Os hieróglifos comumente eram gravados em pedra. Porém, há registros de caracteres, chamados de hieróglifos lineares, pintados a tinta em sarcófagos ou em papiro. Apesar de seu aspecto - próximo ao desenho - ter caráter decorativo, seu mecanismo interno é bastante complicado, pois os sinais ora exprimiam uma palavra, ora um som (HIGOUNET, 2003).

A fase alfabética, por sua vez, caracteriza-se pelo uso de letras. $O$ alfabeto pode ser definido como um conjunto de sinais que representam os sons individuais de uma língua. Os gregos desenvolveram o alfabeto a partir da representação silábica herdada do povo semítico ocidental. Segundo Higounet (2003, p. 60), "o elo mais seguro da pré-história do alfabeto é a escrita pseudo-hieroglífica das inscrições de Biblos, descoberta por M. Dunnand e decifrada por E. Dhorne". É esse registro que contém os rudimentos gráficos da escrita alfabética de que nos servimos até hoje.

Apesar de os fenícios terem reduzido de forma drástica o número dos signos a vinte e dois, "ao custo de ligar um signo a vários sons linguísticos e deixar ao leitor a responsabilidade da escolha correta" (HAVELOCK, 1994, p. 66), foram os gregos os responsáveis pelo passo decisivo para as modificações/criações que a escrita sofreu. Um sistema com menos símbolos possibilitou uma maior combinatória no sistema de caracteres na escrita. Para Havelock (1994), os gregos não só inventaram o alfabeto, como também a cultura letrada e a base letrada do pensamento moderno.

Os sistemas silábicos buscavam representar os sons da fala, tratavam de dar forma às unidades fônicas. Os gregos perceberam que essa prática empirista poderia significar uma quantidade de signos inviável para uma leitura mais diferenciada. Diante desses obstáculos, consideraram a possibilidade de um signo representar uma "mera consoante, um som que, por assim dizer, não existe na natureza, mas só no pensamento" (HAVELOCK, 1994, p. 94). Tomaram emprestado o silabário fenício e decidiram restringir a função da maioria dos signos à simbolização de não sons.

Os sistemas anteriores buscavam imitar a fala; os gregos foram além, visaram:

analisar a unidade linguística em dois de seus componentes teóricos, a vibração da coluna de ar e a ação da boca sobre essa vibração... O sistema grego conseguiu isolar esse não-som e dar-lhe 
sua própria identidade conceitual, na forma do que chamamos uma 'consoante'. (HAVELOCK, 1994, p. 80).

Para eles, a escrita alfabética exige uma análise da forma linguística ainda mais abstrata, uma vez que é necessário detectar, na sequência sonora da palavra, cada uma dessas unidades mínimas - os fonemas - e associá-las à unidade gráfica - a letra - que a representa, o que não é tão fácil quanto possa parecer.

Em alguns contextos, considera-se que os registros escritos têm mais força do que os falados, especialmente em tribunais. Culturas antigas, mesmo conhecendo a escrita, apostavam na oralidade. O grau de crédito da escrita variava de cultura para cultura. Para Clanchy (apud ONG, 1998, p. 112), "os documentos não inspiram confiança imediatamente". Por exemplo, os documentos escritos que comprovavam as idades de herdeiros feudais eram colocados no segundo plano em detrimento do testemunho oral.

É importante salientar que a expressão oral pôde existir independentemente da escrita. Contrariamente, a escrita se constituiu no contexto da oralidade. De todas as línguas faladas, apenas 106 estiveram submetidas à escrita. Dessa forma, para se compreender o que a escrita representa, torna-se essencial a clara compreensão do papel da oralidade em diferentes sociedades (ONG, 1998).

$\mathrm{Na}$ cultura oral, as palavras têm significados somente quando estão sendo ditas. Logo, após a fala, não há volta, pois a manifestação oral desaparece, assim que é pronunciada. Já a escrita alfabética estabelece, no texto, uma sequência que permite ao leitor voltar quando deseja. Para compreender o que é uma cultura oral e sua diferenciação da cultura escrita convém refletir sobre a natureza do som como tal. O som existe apenas quando está deixando de existir. Ele não é apenas perecível, mas é essencialmente evanescente e percebido como evanescente (ONG, 1998). Por exemplo, quando pronuncio a palavra "laranja", no instante em que termino de dizêla, a pronúncia do início da palavra já não se ouve. Desapareceu. Nesse sentido, não conseguimos deter ou possuir o som. A essa altura, cabe perguntar: Como uma cultura oral retém, para posterior recordação, o que foi dito? Na cultura oral, o conhecimento adquirido, para ser armazenado, deve ser constantemente repetido. Assim, algumas estratégias linguísticas eram utilizadas: o pensamento deveria ser expresso em padrões rítmicos, em repetições ou antíteses, em aliterações e assonâncias, por exemplo.

Apesar de serem culturas distintas, precisaríamos visualizar a oralidade e a escrita como sistemas que se conectam, entrelaçados, fazendo parte de um grande 
texto que é a nossa cultura. Como se sabe, mudanças na psique e na cultura estão relacionadas com a passagem da oralidade para a escrita. É importante que se diga que a escrita não foi a única a sofrer transformações: o que temos é uma correlação entre linguagens.

A escrita separa o leitor do escritor. Assim, estabelece condições para a "objetividade", no sentido de um desprendimento ou distanciamento individual, o que não acontece nas culturas orais: estas usam conceitos dentro de quadros de referência situacionais, operacionais, que possuem um mínimo de abstração, que ocorrem próximos ao mundo cotidiano do ser humano (ONG, 1998, p. 61).

Enfim, a escrita não só se especializou para proporcionar uma leitura eficiente, mas também foi sofrendo e provocando mudanças nas mentalidades dos povos letrados, de acordo com os interesses dos diversos grupos sociais: registrar propriedades, ideias, conhecimentos, etc. Como todo instrumento criado pelo homem, a escrita interferiu na forma de organização do pensamento, nas relações sociais, nas condições políticas, econômicas e culturais, ou seja, o homem modificou a realidade por meio de sua criação e é por ela modificado.

Vale destacar também que os suportes nos quais a escrita foi se desenvolvendo influenciaram na evolução desta. Foram muitos e diversificados os materiais utilizados até que chegássemos ao papiro, ao pergaminho e ao papel: pedra, ardósia, tijolo, cacos de cerâmica, mármore, folhas de palmeira, tela, peles de animais, etc. É interessante observar que, dependendo do material que estava sendo utilizado, era possível um traçado diferente. $\mathrm{O}$ uso de materiais mais moles e perecíveis - madeira, casca de árvores, folhas de palmeira, seda, etc. - possibilitou uma escrita mais livre e mais cursiva. Os hieróglifos da escrita egípcia, por exemplo, eram gravados na pedra dura; já a escrita dita cuneiforme dos sumérios utilizava preferencialmente tabuletas de argila fresca, que depois eram cozidas no forno. Os indianos fizeram uso da folha de palmeira; os chineses utilizaram lâminas de bambu e seda crua. Em Roma, era comum o uso de tabuletas cobertas com cera.

Além dos materiais utilizados para o registro da escrita, devemos também nos lembrar dos instrumentos que serviram para o registro da escrita: cinzel, estilete, junco, giz, carvão, pincel, pena, grafite, tinta, etc. Segundo Higounet (2003), o material utilizado para escrita teve igualmente uma importância na variação das formas gráficas. Nos termos do autor, 
para a psicologia dos povos e para os costumes e gestos dos escribas. A esse respeito, temos poucas informações sobre as grandes escritas antigas (p. 21).

Um exemplo disso é a escrita chinesa, que, até o século II a. C., era feita por meio de inscrição em materiais duros como o bronze e a pedra; seus caracteres eram mais difíceis de traçar. Com o uso do pincel, de nanquim e do papel no século I a. C., o processo de escrita ganha mais agilidade e suas formas são simplificadas.

Assim, podemos afirmar que a escrita, especialmente a alfabética, é uma tecnologia que exige ferramentas: lápis, caneta, superfícies cuidadosamente preparadas. É uma tecnologia que passou, e passa ainda, por um processo de expansão que depende não só das disponibilidades dos suportes, mas também das condições oferecidas no ambiente. Como vimos, dependendo dos suportes, dos instrumentos utilizados, a escrita foi assumindo determinado estado, ou seja, ela foi e tem sido resultado da ação do homem no meio e daquilo que o meio pode disponibilizar.

Um ponto a considerar, quando refletimos sobre a cultura escrita, é perceber a diferenciação entre a manuscrita e a tipográfica. É interessante observar que, nas culturas manuscritas, quando se liam os textos escritos, assumia-se uma postura oral/auricular. Segundo Ong (1998), provavelmente esse fato foi decorrência da dificuldade de lê-los, pois, muitas vezes, as palavras eram grafadas juntas ou em espaços mínimos. Com isso, localizar qualquer trecho lido ficava muito difícil. Assim, estratégias para a memorização continuavam a ser utilizadas. Somente com a impressão - era tipográfica -, as palavras passaram a ser "arranjadas" no espaço de maneira que ficassem mais legíveis e, assim, a leitura tornou-se mais fluente.

McLuhan (1968) descreveu os modos pelos quais as formas de experiência de visão e de expressão mental foram sendo alteradas, em decorrência, primeiro, do alfabeto fonético e, depois, pela impressão tipográfica. Concluiu então que, apesar de a palavra impressa ter conferido ao homem uma linguagem de pensamento, ela o deixou completamente desarmado para enfrentar a linguagem de sua própria tecnologia eletromagnética. Com a invenção do alfabeto fonético, reduziu-se o uso simultâneo de todos os sentidos: a expressão oral foi reduzida a um simples código visual. "Hoje, pode-se efetuar essa espécie de translação numa ou noutra direção, através de uma variedade de formas espaciais, as quais chamamos de 'media', ou 'meios de comunicação'” (MCLUHAN, 1977, p. 76). 
Para McLuhan (2002, p. 107), as escritas pictográficas e hieroglíficas representam "uma extensão do sentido visual para armazenar e facilitar o acesso à experiência humana". Já o alfabeto fonético - com poucos sinais - reforçou a separação entre os sentidos auditivo e visual. Para o autor, essa separação - visão, som e significado - provocou efeitos tanto sociais como psicológicos. $\mathrm{O}$ autor lembra também que o processo civilizatório se baseia na alfabetização, pois só assim foi possível um processamento uniforme de uma cultura pelo sentido da visão, projetado no espaço e no tempo pelo alfabeto.

De fato, o grande salto da cultura oral para a escrita, da audição para a visão só aconteceu com a implantação da tecnologia de Gutenberg. A máquina impressora propiciou, simultaneamente, a necessidade e a possibilidade de um novo modo de expressão. A cultura oral sofreu transformações provocadas pela era mecânica - era de Gutenberg - e, atualmente, a cultura escrita está também sofrendo transformações decorrentes da era eletrônica. Voltaremos a esse assunto mais adiante, na discussão sobre as escritas contemporâneas.

Retomando a questão das implicações da evolução da escrita, cabe destacar que, com o alfabeto fonético, trocou-se a audição pela visão. Quando a tecnologia mecânica e tipográfica se estabelece, o conflito entre a tendência auditiva e a visual se intensifica. Para McLuhan (1977), na era manuscrita, a cultura ainda mantém "as funções audiotácteis da sensibilidade humana num grau incompatível com a abstração visual ou a translação de todos os sentidos para a linguagem de espaço unificado, contínuo e pictórico" (p. 161). Foi por meio do alfabeto fonético e, principalmente, com o advento da tipografia que se estabeleceu uma cisão entre visão e audição. A criação da máquina impressora transformou o homem tribal em "homem civilizado, de organização visual, com hábitos, atitudes e direitos iguais aos outros indivíduos civilizados” (p. 101). Assim, uma das consequências da invenção da escrita foi o processo de destribalização.

$\mathrm{O}$ autor defende a ideia de que a estrutura da sociedade, sobretudo o modo como o ser humano pensa, se alterou com a introdução da escrita. Para ele, toda a tecnologia que amplia os sentidos produz consequências provenientes do modo com que ela foi (e é) assimilada e incorporada. Ao divulgar a palavra para locais distantes e em larga escala, as pessoas puderam ampliar o seu espaço de vida, conhecer outros povos, outros costumes, outras culturas. Foi possível, então, falar para muitas pessoas ao mesmo tempo. Falar e divulgar a mesma língua foram elementos aglutinadores e reforçadores dos laços nacionais. 
Antes da invenção da imprensa, a escrita tinha sua divulgação limitada, pois era feita à mão. Copiar levava muito tempo e os instrumentos eram muito rudimentares. Logo, o número de pessoas que lia e escrevia era bastante restrito. Por isso, a cultura manuscrita não conseguiu divulgar o conhecimento em larga escala, como ocorreu na era Gutenberg.

Os registros do homem estiveram sempre relacionados às condições vivenciadas pelos indivíduos nas diferentes épocas. Assim, desde o início dos tempos, as inovações e rupturas referentes aos suportes foram se modificando. Da mesma forma que as escritas - alfabéticas ou pictográficas - foram registradas em diferentes suportes, as escritas contemporâneas também o são.

Como já assinalamos, para escrever, é necessário o uso de algum suporte e de instrumentos para se fazerem marcas ou incisões. Dessa forma, ao mesmo tempo em que se aperfeiçoava a escrita, também se buscavam outros suportes/meios para seu registro. O livro impresso levou muito tempo para ser difundido. Foi ele o primeiro produto cultural de consumo de massa ao constituir, em si mesmo, uma forma especializada de comunicação e de espacialização do pensamento: "A palavra impressa foi a primeira coisa produzida em massa, foi também o primeiro "bem" ou "artigo de comércio" a repetir-se ou reproduzir-se uniformemente" (MCLUHAN, 1977, p. 177).

Consequentemente, se a palavra oral e a palavra escrita garantiram ao homem o direito de comunicar-se, a escrita parece ter-se desenvolvido dotada de poderes mais rigorosos: acaba estabelecendo uma separação social entre alfabetizados e não alfabetizados. Para melhor compreendermos essa questão, abordaremos no item seguinte o conceito de alfabetização ainda bastante recorrente nas orientações e práticas de ensino e aprendizagem da língua escrita.

\section{O conceito de alfabetização no contexto atual}

A linguagem oral é completamente natural aos seres humanos. Qualquer criança, desde que disponha de condições biológicas adequadas, é capaz de aprender a falar, em qualquer cultura. A criança que se inicia na alfabetização é um falante da sua língua, porém ainda não escreve convencionalmente.

Apesar de vivermos em contextos completamente letrados nos quais a escrita é constantemente colocada sob nossos olhos, a sua aprendizagem requer ensino. A escrita constitui uma codificação da linguagem oral, única forma da 
língua que é "natural", no sentido de que sua utilização, na produção do discurso, não requer nenhum procedimento de instrução ou educação.

Ao analisar a construção da escrita pela criança, Vigotski (1994) considera que esta pode desenvolver a linguagem falada por si mesma, mas a linguagem escrita exige um treinamento artificial. Vigotski assumiu uma abordagem genética, ou seja, interessou-se pelo processo de sua aquisição, o qual se inicia muito antes de a criança entrar na escola. Esse processo passa pela compreensão de que a escrita é um sistema de signos que não tem significado em si. Para o autor, a aprendizagem da língua escrita não é uma questão de memorização de um código, mas a compreensão de que é um sistema de representação da realidade.

Luria (1986), um dos colaboradores de Vigotski, desenvolveu estudos experimentais sobre o desenvolvimento da escrita e constatou que, antes da alfabetização, a criança usa a escrita de forma puramente externa, intuitiva, não como instrumento para recordar, para representar algum significado. Não há escrita, mas simples rabiscos. "A conexão entre rabiscos da criança e a ideia que pretendem representar é puramente externa” (LURIA, 1986, p. 150).

De acordo com esse autor, o período em que a criança começa a rascunhar seus primeiros traços na escola não corresponde ao primeiro estágio do desenvolvimento da escrita. Ao entrar na escola, a criança já possui um rol de habilidades e destrezas que lhe permitirá aprender a escrever. A gênese desse processo remonta a momentos anteriores aos quais ele denomina pré-história do desenvolvimento das formas superiores do desenvolvimento infantil.

Num estágio posterior, a criança começa a dispor de seus rabiscos em um padrão ao qual associa sentenças ou palavras que lhe são sugeridas. Seus rabiscos passam a significar alguma coisa e cumprem uma função mnemônica, de auxiliar a memória. Luria mostrou que o ato precede a compreensão, ou seja, antes que a criança compreendesse o sentido e o mecanismo da escrita, ela já efetuou inúmeras tentativas para elaborar métodos primitivos. Estes são, para ela, a pré-história de sua escrita, ou seja, o percurso gradual diferenciado dos símbolos usados por ela.

Tanto para Luria como para Vigotski, a escrita é uma atividade sociocultural fundamental que, depois de assimilada, transforma as funções psíquicas superiores. $^{2}$ É um instrumento para certas ações psicológicas, possibilitando

2 Ações conscientemente controladas, atenção voluntária, memorização ativa, pensamento abstrato, comportamento intencional são ações tipicamente humanas e são consideradas funções psicológicas superiores. Essas funções se diferenciam de mecanismos mais elementares, como reflexos, reações automáticas e associações simples. As funções mentais superiores são construídas ao longo da história 
a ampliação da capacidade da memória, transmissão e recuperação de ideias, conceitos e informações.

À luz da teoria construtivista, que vê a criança como sujeito da sua aprendizagem, Emilia Ferreiro e Ana Teberosky, ao analisarem as interpretações que as crianças dão à escrita, chegaram a algumas conclusões quanto ao processo por meio do qual se dá a alfabetização. Esse processo, denominado pelas autoras de psicogênese da língua escrita, tem mostrado que a alfabetização tem início muito antes do contato da criança com o ensino formal. Através de revistas, jornais, cartazes, rótulos, televisão, etc. (e mais recentemente, computadores, celular, iPhone), a linguagem escrita já chamou a sua atenção, em maior ou menor grau, levando-a a formular hipóteses sobre o sistema. Esse processo evolui e muda com a idade, sendo difícil estabelecer uma relação direta entre o ensino sistemático escolar e essa evolução.

De acordo com Ferreiro (2001), os sistemas de escrita são produtos culturais da sociedade e a alfabetização representa o processo de apropriação, pelo aluno, de um conhecimento específico, ou seja, representa a reconstrução do código linguístico, entendendo-se reconstrução como a compreensão do funcionamento desse código. Tal compreensão é algo mais abrangente que a simples codificação e decodificação da palavra.

Nessa concepção de alfabetização, a leitura é vista como um processo de descoberta, atribuição de sentidos e de significados, os quais deverão ser construídos socialmente. É uma atividade que possibilita ao sujeito ter acesso aos bens culturais produzidos pela sociedade e, ao mesmo tempo, amplia sua compreensão da realidade. É uma ação essencial para uma participação consciente do sujeito na realidade histórico-social.

Assim, a alfabetização não é um estado, mas um processo. Ela tem início quando nascemos e não termina nunca. A criança, durante seus primeiros anos de vida, encontra-se em interação com diferentes sujeitos - adultos e outras crianças - o que vai lhe permitindo atribuir significados a diferentes ações, diálogos e vivências.

Ela não recebe a língua pronta para ser usada; ela a constrói em uso; é nela e através dela que se comunica, se constitui, se transforma, e transforma a própria língua. Segundo Bakhtin (1995, p. 108), “os indivíduos não recebem a língua pronta para ser usada; eles penetram na corrente da comunicação verbal; ou

social do homem e envolvem, necessariamente, relações entre o indivíduo e o mundo, que não são diretas, mas mediadas pela cultura. 
melhor, somente quando mergulham nessa corrente é que sua consciência desperta e começa a operar".

Vale lembrar ainda que nós não somos igualmente alfabetizados para qualquer situação de uso da língua escrita. Temos mais facilidade para ler determinados textos e evitamos outros. Nesse sentido, o conceito de alfabetização também muda de acordo com as épocas, as culturas e a chegada da tecnologia. O mundo contemporâneo, permeado por linguagens diversas, tem exigido uma alfabetização que não considere apenas a leitura da escrita alfabética. Hoje se faz necessário buscar caminhos, elementos, estratégias que possibilitem ler diferentes textos: verbais, visuais, audiovisuais, midiáticos, digitais.

Sabemos que a escrita é um objeto cultural bastante valorizado na sociedade, e que a escola se propõe a trabalhá-la, pois grande parte das informações, reflexões e discussões sobre a realidade são veiculadas pela escrita. Sabemos também que muitas informações estão sendo transmitidas por outros sistemas e que, diferentemente do que acontece com a escrita e a leitura da palavra, são pouco trabalhados/conhecidos. O termo "alfabetização" tem sido utilizado apenas para designar a ação de ler e escrever textos a partir do domínio do código alfabético. O conceito de "alfabetização semiótica", que propomos neste trabalho, considera a escrita em expansão, compreendendo o mundo como linguagem: um grande texto.

Antes de uma discussão mais aprofundada dessa concepção, faremos um breve relato dos processos comunicacionais desde a cultura tipográfica até as tecnoimagens - escritas contemporâneas. Essa discussão nos ajudará a melhor explicitar o conceito de alfabetização semiótica.

\section{As escritas contemporâneas}

Para realizar uma discussão sobre as escritas contemporâneas, recorremos a alguns autores que ilustram a problemática trazida pela cultura em expansão. Inicialmente, evidenciamos algumas ideias de McLuhan (1977, 2002), Vilém Flusser (1983, 2002) e Lorenzo Vilches (2003).

No livro Os meios de comunicação como extensões do homem, McLuhan (2002) afirma que todas as tecnologias criadas pelo homem serviram de extensões de seu sistema físico e nervoso. Para defender tal postulado, ele se propôs a descrever e analisar 27 tecnologias: a palavra falada e a escrita, o número, as estradas e as rotas de papel, o vestuário, a habitação, o dinheiro, os relógios, a tipografia, as histórias 
em quadrinhos, a palavra impressa, a roda, a bicicleta, o avião, a fotografia, a imprensa, o automóvel, o anúncio, os jogos, o telégrafo, a máquina de escrever, o fonógrafo, o cinema, rádio e televisão, os armamentos, a automação. Segundo esse autor, as tecnologias levaram o homem, do mundo linear e mecânico da revolução industrial, para o novo mundo auditáctil e retribalizado da era eletrônica. Assim, cada nova tecnologia provocou um movimento de expansão cultural e a intenção de McLuhan era demonstrar que todas as tecnologias geram novos padrões de vida. Para ele, o meio é a mensagem porque "é o meio que configura e controla a proporção e a forma das ações e associações humanas” (2002, p. 23).

Considerando-se que a escrita vem sendo explorada de diversas formas - a escrita analítica, a sintética, alfabética, a manuscrita, a tipográfica e hoje a eletrônica digital - podemos dizer que temos uma escrita em expansão, ou seja, um processo provocado pelos suportes, pelas mediações, pelas interações, enfim, pela ação do homem no meio e do meio com relação ao homem.

Anísio Teixeira, já em 1970, ao analisar textos de McLuhan, chama a atenção para não nos entregarmos cegamente aos efeitos do suporte/meio,

e ao seu uso e exploração para fins que talvez não devêssemos aceitar [...]. A confusão entre a tecnologia e o conteúdo de sua atuação levou-nos a não tomar consciência dos seus efeitos, os quais ligávamos, não ao medium pròpriamente dito, mas ao curso normal, melhor diríamos, cego, do "progresso" humano (TEIXEIRA, 1970, p. 8).

$\mathrm{Na}$ verdade, as observações feitas por McLuhan para a era manuscrita e, depois, para a era tipográfica, sofreram modificações quando o homem se deparou com a era eletrônica, marcada pela eletricidade, rapidez, movimento.

Para o autor, uma das maiores mudanças de todo o tempo histórico é a passagem da tecnologia da roda para a tecnologia do circuito eletrônico. Na era tipográfica, o homem é convidado a compreender a organização visual do espaço. Na tecnologia elétrica, o sentido visual é abafado e há o predomínio da sinestesia. A nova criação é integrada no que já foi realizado pelo homem. O novo e o velho são trabalhados juntos, sofrem ajustes e provocam mudanças. Por exemplo, quando o homem cria a escrita alfabética e, depois, a possibilidade de divulgá-la com rapidez (era tipográfica), a escrita sofre modificações. Assim, também os meios mecânicos não se extinguiram com o surgimento da etapa eletrônica.

Para a compreensão dos meios, seria necessário ter consciência de que cada nova tecnologia introduzida produz um entorpecimento na região recém- 
prolongada. Quando intensificamos algum sentido, deixamos de lado outros, ou seja, se a visão for intensificada, o tato, a audição e o paladar serão afetados. Assim, "qualquer invenção ou tecnologia é uma extensão ou auto-amputação de nosso corpo, e essa extensão exige novas relações e equilíbrios entre os demais órgãos e extensões do corpo" (MCLUHAN, 2002, p. 63).

Um aspecto importante levantado por McLuhan diz respeito ao fato de que ainda não estamos preparados para lidar com as novas extensões. Diz ele: "nenhuma sociedade teve um conhecimento suficiente de suas ações a ponto de desenvolver uma imunidade contra suas novas extensões ou tecnologias" (2002, p. 84).

Interessante que, para esse autor, o caminho para a imunidade passa pela arte. É o artista quem melhor está equipado para lidar com as tecnologias/meios, justamente porque este é competente nas mudanças da percepção. Como assinala:

O artista é o homem que, em qualquer campo, científico ou humanístico, percebe as implicações de suas ações e do novo conhecimento de seu tempo [...]. O artista pode corrigir as relações entre os sentidos antes que o golpe da nova tecnologia adormeça os procedimentos conscientes. Pode corrigi-los antes que se manifestem o entorpecimento, o tateio subliminar e a reação. (MCLUHAN, 2002, p. 86).

De fato, quando utilizamos uma tecnologia ou, mais especificamente, uma extensão de nós mesmos, isso nos leva a adotá-la. Ler o jornal - uma página impressa - é aceitar essa extensão de nós mesmos, é "sofrer o adormecimento ou a transferência da percepção que necessariamente se segue" (MCLUHAN, 2002, p. 64). O autor afirma ainda que a dificuldade que temos para a compreensão da variedade iconográfica do mundo da publicidade é decorrente da maior atenção dada ao conteúdo do que à forma. O homem alfabetizado, acostumado com o livro/ escrita impressa, supõe, muitas vezes, que a imprensa/jornal seria melhor sem os anúncios, pois "um anúncio requer mais esforço e pensamento, mais espírito e arte do que qualquer texto de jornal ou revista" (2002, p. 237). É importante reforçar que a era eletrônica criou condições para a instauração da sociedade midiática e, com isso, a linguagem audiovisual assumiu um espaço significativo: passou a ser a linguagem dominante.

Para McLuhan, a era eletrônica pode ser considerada como um retorno (retribalização): algo que deixamos de lado e que estamos novamente assumindo. 
Vilém Flusser ${ }^{3}(1983,2002)$, no entanto, se contrapõe a essa visão de retorno, ao afirmar que o contexto atual não deve ser visto como uma volta ao passado, mas como algo novo e desconhecido. No trabalho de Flusser, percebemos um tom menos otimista do que no de McLuhan. Embora demonstre preocupação com relação ao entendimento do contexto tecnológico, Flusser não deixa de acreditar que somos capazes de refletir a respeito desse contexto. Parece que pede calma diante das novidades tecnológicas: é preciso conhecê-las e entendê-las. Essa visão diferenciada, esse tom menos otimista, essa preocupação em conhecer o contexto atual (os aparelhos tecnológicos), enfim, seu discurso não contradiz, mas amplia as discussões já feitas por McLuhan.

Ao fazer um levantamento histórico dos processos comunicacionais e culturais, Flusser (1983) aponta dois períodos: pré-alfabético e pós-alfabético, antes e depois da escrita alfabética. No período pré-alfabético, o homem fez uso da imagem para recriar o mundo e para se comunicar. Imagens são superfícies, planos bidimensionais, são mediações entre o homem e o mundo. No entanto, essas imagens, apesar de representarem o mundo para o homem, simultaneamente, se interpõem entre o homem e o mundo.

Ao construir as imagens, o homem intencionava que elas servissem de referência do mundo, entretanto passam a constituir obstáculos, uma vez que o homem passa a viver em função das imagens (FLUSSER, 2002). Como consequência, não consegue decifrar as imagens como significados do mundo, mas passa a olhar o mundo como conjunto de imagens. Tal inversão recebe o nome de idolatria. Com isso, sofre um processo de alienação: esqueceu o porquê e o para quê de haver construído a imagem. Não consegue mais perceber que as imagens deveriam tão somente servir para orientá-lo no mundo: e passa então a ser guiado por elas. É como se as imagens tivessem "vontade própria"; fossem algo separado do ser humano, independente, agindo por si sós. "A imaginação torna-se alucinação e o homem passa a ser incapaz de decifrar imagens, de reconstruir as dimensões abstraídas" (FLUSSER, 2002, p. 9).

3 Vilém Flusser (1920-1991) nasceu em Praga, na antiga Thecoslováquia; estudou Filosofia na Universidade Karlov. Contudo, antes mesmo de terminar seus estudos, precisou fugir para o Brasil, quando seu país foi invadido pelos nazistas. Durante alguns anos, trabalhou no comércio e na indústria, até que, por volta de 1960, resolveu dedicar-se à vida intelectual. Integrou-se à cultura brasileira, foi professor no ITA (Instituto Tecnológico de Aeronáutica), na FAAP (Fundação Armando Álvares Penteado) e na USP (Escola Politécnica), lecionando diversas disciplinas, organizando seminários e conferências. Dentre os muitos estudos realizados, vamos destacar, para este texto, os livros Póshistória e Filosofia da caixa preta. 
Nesse sentido, as imagens não devem ser vistas como conjuntos com significados claros, evidentes; elas oferecem, aos seus receptores, possibilidades de interpretação, por isso são símbolos subjetivos, conotativos.

Quando olhamos uma imagem, a nossa tendência é vaguear pela superfície, somos capazes de voltar para rever detalhes. O olhar é circular: o tempo projetado para observar a imagem é o eterno retorno. Esse movimento circular - voltar para elementos já vistos - faz com que as relações significativas sejam estabelecidas. Para Flusser, o tempo é circular, mágico: "um elemento explica o outro, e este explica o primeiro. O significado das imagens é o contexto mágico das relações reversíveis" (2002, p. 9).

A escrita linear (por exemplo, o alfabeto latino ou as cifras árabes) surgiu para resolver "problemas" provocados pela imagem: a escrita foi uma revolução contra as imagens. Desse modo, o texto ${ }^{4}$ passa a explicar a imagem, numa tentativa de torná-la menos ambígua: "A escrita foi inventada quando a função tapadora, alienante, das imagens ameaçava sobrepor-se sobre a sua função orientadora" (FLUSSER, 1983, p. 98).

Apesar de o homem intencionar, por meio da escrita, representar, de forma objetiva, o mundo circundante, ele não o conseguiu. A escrita, por ser abstrata, afastou-se ainda mais do mundo. Os textos não representam o mundo diretamente, pois são conceitos que não significam fenômenos: significam ideias. Segundo Flusser, "decifrar textos é descobrir as imagens significadas pelos conceitos. A função dos textos é explicar imagens, a dos conceitos é analisar cenas. Em outros termos: a escrita é metacódigo da imagem" (2002, p. 10).

A escrita também não possibilitou que o homem pudesse "ler" o mundo de maneira explícita, clara, transparente. Assim como a imagem, a escrita também é signo; seu propósito é mediar a relação entre homem e mundo. Contudo, ao realizar tal feito, a escrita, em vez de ajudar a esclarecer o mundo/imagem, obstacularizou as imagens que pretendia representar. Com isso, o ser humano não conseguiu decifrar textos e reconstruir as imagens abstraídas. O que é pior, segundo Flusser, o homem "passa a viver não mais para se servir dos textos, mas em função destes" (2002, p. 11). Se antes, com as imagens, o homem sofria um processo de idolatria, com a escrita se depara com a textolatria. Para Flusser, esse fenômeno assumiu proporções sérias durante o século passado: “A crise dos textos implica o naufrágio da História toda que é, estritamente, processo de

4 Para Flusser, texto são signos da escrita em linhas. 
recodificação de imagens em conceitos. História é explicação progressiva de imagens, desmagicização, conceituação"5 (2002, p. 11). Logo, quando os textos não significam imagens, as explicações tornam-se supérfluas, desnecessárias, absurdas, disparatadas.

Com a finalidade de superar essa crise, o homem inventa as imagens técnicas: imagens provenientes de aparelhos. Flusser (1983) esclarece que as imagens técnicas ${ }^{6}$ (ou tecnoimagens) são diferentes das imagens tradicionais: elas são póshistóricas, ou seja, elas foram produzidas depois da escrita alfabética, linear.

A invenção das imagens técnicas é tão significativa como a criação da escrita. Por elas terem sido criadas para eliminar os textos, pensava-se que eram mais objetivas, explícitas. A aparente objetividade, porém, é ilusória: elas são tão simbólicas quanto as imagens tradicionais e devem ser decifradas por quem deseja construir seus significados. Além disso, são “compostas por símbolos extremamente abstratos: codificam textos em imagens, são metacódigos de textos. [...] Decifrá-las é reconstituir os textos que tais imagens significam" (FLUSSER, 2002, p. 14). Assim, ao decifrarmos tais imagens, o que vemos são determinados conceitos relativos ao mundo. Diferentemente do que acontece com as imagens tradicionais, é difícil perceber que há um agente humano (por exemplo, o fotógrafo) que se coloca entre elas e seu significado.

Para Flusser (2002), as imagens técnicas teriam, então, a tarefa de reunificar a cultura por meio de um código geral. Tais imagens deveriam constituir um denominador comum entre o conhecimento científico, a experiência artística e a vivência política. Toda imagem técnica deveria representar, ao mesmo tempo, conhecimento, vivência e modelo de comportamento: verdade - beleza - bondade.

As imagens técnicas, porém, não explicitam o conhecimento científico, "mas o falseiam; não reintroduzem as imagens tradicionais, mas as substituem; não tornam visível a magia subliminar, mas a substituem por outra. Nesse sentido, as imagens técnicas passam a ser 'falsas', 'feias' e 'ruins"' (2002, p. 18) e não foram capazes de reunificar a cultura, "mas apenas de fundir a sociedade em massa amorfa" (p. 18). Atualmente, a maioria das mensagens que nos informam a respeito do mundo são as imagens técnicas. São as imagens, e não mais os textos escritos, que são as mídias dominantes. Planos, como fotografias, telas de cinema, $\mathrm{TV}$, computadores, celulares tornaram-se os portadores das informações que nos 
programam. É importante perceber que essas imagens são pós-alfabéticas e não pré-alfabéticas como eram as imagens no passado; são imagens produzidas por aparelhos.

Para Flusser, a contrarrevolução das tecnoimagens é superável apenas graças a uma capacidade nova, a ser desenvolvida, e que pode ser chamada "tecnoimaginação": capacidade de decifrar imagens técnicas. Tal capacidade está relacionada com o pensamento formal, tal como este vai se estabelecendo na informática, cibernética e na teoria dos jogos. Se não conseguirmos dar esse passo rumo ao "nada" - estrutura a ser desenvolvida -, jamais conseguiremos emancipar-nos do pensamento e da ação programada por tecnoimagens.

Para esse autor, o nosso mundo vem se tornando, cada vez mais, sem sentido e estamos cercados por objetos tolos (os gadgets), que nos programam. Somos programados para não poder sobreviver sem esses objetos e, com isso, as sociedades vivem guiadas pela estupidez, pois o processo de aculturação (produção de instrumentos) possibilitou ao homem sua emancipação da natureza. Mas, em vez de emancipá-lo, programou-o.

Enfim, as reflexões feitas por Flusser sobre as imagens técnicas propiciaram condições para a construção do conceito de pós-história, tomando como referência as mudanças ocorridas nos processos comunicacionais e culturais nos últimos tempos. Para ele, a história teria início com o tempo/escrita linear e o seu modelo é o da causalidade. Já a pós-história teria sido inaugurada com as imagens técnicas, em especial, a fotografia. A pós-história - processo circular que retraduz textos em imagens - é marcada pela passagem do pensamento causal e linear para o pensamento estruturado por códigos pós-textuais.

Apesar de vivermos em contextos nos quais a maioria das mensagens é irradiada pelas superfícies - imagens técnicas -, ainda temos muita dificuldade de pensar e entender a consciência pós-histórica. Por ser um processo recente, não estamos conseguindo ter a devida clareza sobre ele e, por isso, acabamos nos deixando apenas no nível da historicidade. Da mesma forma que os não alfabetizados são em relação aos textos escritos, nós somos em relação às tecnoimagens.

Ainda assim, mesmo que as chances de consciência crítica da maioria das pessoas sejam ínfimas, devemos acreditar nelas. Tanto McLuhan como Flusser afirmam que os processos comunicacionais que o homem foi criando, no transcorrer de sua existência, provocaram modificações na sua forma de ser e de estar. São transformações físicas e psíquicas provenientes das criações humanas 
que merecem ser estudadas, investigadas e analisadas. Por exemplo, quando o homem criou a escrita, ele não conseguiu visualizar as consequências desse ato. Aliás, hoje também não estamos conseguindo visualizar, com clareza, o que significa conviver com as imagens técnicas. Enfim, compreender como somos afetados/dirigidos pelo processo comunicacional se faz necessário. Essa é uma das preocupações da alfabetização semiótica.

As criações do homem sempre provocaram diferentes tipos de reações: medo, satisfação, orgulho, felicidade, desprezo, etc. Enfim, sentimentos contraditórios. Rocco (1999) chama a atenção para o fato de a escrita ser exemplo dessa questão. Esse processo de criação foi criticado - de diferentes formas e por razões diversas - por Platão, Bacon, Rousseau, Bergson, Lévi-Strauss. A autora lembra que Platão condenava a escrita, pois ela, ao invés de perpetuar a memória, colaborava para o seu esquecimento.

O mesmo aconteceu com o advento da televisão. Pensava-se que esse meio eletrônico e audiovisual, por ser verbal, uniformizaria a fala das pessoas, fazendo com que se distanciassem da escrita. Segundo Rocco,

ninguém escreve menos pelo fato de se relacionar mais, enquanto assiste a TV, com a modalidade oral [...] a natureza da relação que preside os atos diversos da fala nada tem a ver com a natureza das operações de recepção de TV. E o mesmo se dá com a produção da escrita em suas formas e motivações tão diversas (p. 79).

A preocupação de que o "antigo" pudesse desaparecer ou ser substituído pelo "novo" fez com que, em alguns momentos, assumíssemos uma postura ingênua perante as transformações. Muitas vezes, deixamos de perceber que essas substituições ocorreram mais nos suportes do que nos produtos culturais neles inseridos. Acreditava-se que o cinema iria substituir a fotografia, que a televisão ocuparia o lugar do cinema, mas isso não aconteceu. O que temos é uma convivência de diferentes criações culturais do homem, interagindo umas com as outras (Rocco, 1999).

Apesar desse convívio, aparentemente passivo, é importante perceber que no contexto atual - mídias eletrônicas -, o modo como as mensagens estão organizadas e conectadas é tão significativo como o que está sendo transmitido. Exemplificando, podemos citar o texto eletrônico da Internet. Produto verbal diferente, veiculado por um novo suporte - computador - atua "tanto sobre a 
natureza e feição dos textos quanto sobre os processos de apropriação e significação por parte dos leitores" (ROCCO, 1999, p. 83).

Lorenzo Vilches (2003), no texto Tecnologia digital: perspectivas mundiais, discute as transformações que vêm ocorrendo na sociedade contemporânea, decorrentes, principalmente, das interações com as novas tecnologias. Hoje, deparamo-nos com novas instâncias de mediação na cultura, na educação e nos serviços de consumo.

Para o autor, a situação atual, marcada por extrema complexidade, pode ser caracterizada como a era de transição ou migração digital. O conceito de migração é mais amplo e abrangente do que a união, por exemplo, da televisão com a informática e as telecomunicações. Essa nossa era comporta mudanças estruturais: tanto a matéria e a forma dos meios de comunicação como a circulação dos conhecimentos e os vínculos que são estabelecidos na rede social já se transformaram (VILCHES, 2003). A migração digital estimula conexões e interações inesperadas; propicia novas redes de comunicação e interação. São essas situações inusitadas que precisamos investigar.

Segundo Vilches (2003), os meios de comunicação encontram-se submetidos a uma grande convergência assimétrica. $\mathrm{O}$ encontro de tecnologias - movimentos migratórios da televisão e da Internet - produz importantes efeitos culturais e tem relação com as novas formas do conhecimento e da educação. Exemplificando essa questão, o autor afirma que a televisão educativa fracassou, pois nunca chegou a ser um meio para a educação. Vista como um espaço de diversão contemplativo, a função principal no meio consistia em ver. A Internet, diferentemente, é um meio interativo e não tem sentido como máquina passiva.

Não é nossa intenção aqui aprofundar essas discussões, mas reforçar a ideia de que os processos comunicacionais caminham muito mais num mecanismo de expansão, incorporação, do que de exclusão, substituição. Citando um trecho de Vilches (2003) do texto Conhecimento e ação, lembramos que não é apenas contemplando que conheceremos/entenderemos a nossa rede cultural, o nosso grande texto:

Não se aprende a ler e escrever apenas olhando pessoas que lêem e escrevem; aprende-se escrevendo e lendo. Mas mesmo que se queira defender o valor informativo da televisão, além de puro entretenimento - como acreditamos que se deva fazer -, não se pode confundir informação e conhecimento. A informação não produz conhecimento. $\mathrm{O}$ conhecimento não se produz sem a ação 
mediadora de algum sujeito. O conhecimento não se "partilha", por nenhum meio. O que se "partilha" é informação. O conhecimento tem de ser adquirido. Assim como não se pode confundir o manual de instruções para usar tecnologias, e o conhecimento que só a ação interativa pode gerar. Para comunicar-se por correio eletrônico, não basta estudar as especificações técnicas de um modem. Assim, portanto, são inseparáveis a finalidade do processo comunicativo e o meio usado, mas não se pode confundir a ação de um sujeito e a tecnologia. A mediação tecnológica inclui também a mediação linguístico-comunicativa e a mediação material; ambas são inerentes ao conceito de mediação tecnológica (p. 203).

Resumidamente, é possível apontar que, embora não haja uma forma única de pensar as influências da escrita no pensamento do homem, todos os autores apresentados anteriormente concordam com uma premissa básica: as diferentes escritas e seus suportes provocam mudanças cognitivas que compõem o pensamento. É, portanto, com base nessa premissa, que propomos, para entender a dinâmica cultural e a expansão da escrita, a alfabetização semiótica.

\section{Escrita em expansão: o conceito de alfabetização semiótica}

Para compreender que a escrita sofre um processo de expansão é necessário enxergar que esse fato é consequência da maneira como a nossa cultura vem se constituindo. Entendida como grande texto, a cultura é constituída por diversos sistemas semióticos, interconectados, em constante diálogo, num crescente processo de experimentação, transformação e expansão. Logo, cultura é algo vivo: um eterno acontecer. Para o pesquisador Geertz, a cultura é vista como um texto portador de sentidos/ significados que deve ser resgatado pela interpretação. Nos termos desse autor,

o homem é um animal amarrado a teias de significados que ele mesmo teceu, assumo a cultura como sendo essas teias e a sua análise; portanto, não como uma ciência experimental em busca de leis, mas como uma ciência interpretativa, à procura do significado (GEERTZ, 1989, p. 15).

É dentro dessa estrutura aberta - grande texto -, tecida pela ação do homem, que a cultura escrita vem assumindo diferentes feições: manuscrita, impressa, eletrônica, digital. Podemos dizer que a escrita em expansão corre por duas dimensões: por 
campo de cobertura e por campo de sentidos. A expansão da escrita por campo de cobertura - escrita tipográfica, eletrônica - tem sido, nos últimos tempos, muito maior do que a expansão por campo de sentido, ou seja, a escrita está espalhada em muitos suportes e sendo divulgada para diferentes lugares, mesmo que não tenhamos condições de atribuir a ela sentidos mais consistentes, desconhecemos como ela vem se organizando, se estruturando. Ainda, exemplificando, podemos perceber a escrita em expansão, quando ela se dissipa nos aparelhos (televisão, Internet, celular, etc.) que permitiram sua disseminação e expansão por cobertura. Como sabemos, a velocidade dos deslocamentos é avassaladora. Logo, se pretendemos ter alguma influência sobre nossa próxima escala, é bom avançarmos no campo dos sentidos.

Já a expansão por sentido ocorreria tanto no momento da interpretação do que se comunica/divulga, como no processo de emissão do que se pretende comunicar. Assim, a expansão por sentido pode ser definida como o próprio ato de comunicação. É importante que se diga que comunicação deve ser entendida como um processo no qual as pessoas almejam a construção de significados partilhados; não é apenas transmissão de informação, mas um processo de interpretação.

Essas duas dimensões - sentido e cobertura - vêm apresentando um crescimento desproporcional, ou seja, a expansão por sentidos não consegue acompanhar a expansão por cobertura.

Machado (1996), ao discutir a expansão da escrita no confronto de múltiplas escrituras, já apontava a necessidade de se repensar o conceito de alfabetização, considerando o desenvolvimento da escrita eletrônica. Parece-me que a pesquisadora já estava atenta ao avanço de cobertura que as tecnologias propiciavam e, com isso, à importância de ampliarmos nossa competência textual rumo ao campo de sentidos.

Para Machado (1996), a criança, antes de ir para escola, já presenciou, na rua ou na televisão,

\footnotetext{
"palavras em movimento, progredindo em diversas direções e apresentando infinitos padrões gráficos; palavras e frases, textos em expansão. Logo, o processo de alfabetização não é mera sopa de letrinhas, mas assimilação e desenvolvimento de competências textuais" (p. 52).
}

O desenvolvimento de competências para a construção de significados/ sentidos partilhados pressupõe o desenvolvimento da capacidade metalinguística 
da produção da linguagem, ou seja, a percepção das possíveis traduções entre os sistemas semióticos. Quando os sistemas entram em conexão, eles não se anulam, mas se reelaboram, se expandem: coevoluem.

O entendimento da dinâmica cultural pressupõe o conhecimento dessas conexões, traduções, enfim, do processo de experimentação. É por meio dessa competência/conhecimento textual - alfabetização semiótica - que iremos avançar no campo dos sentidos.

Parece-nos que ainda estamos distantes de um ensino que considere a expansão da escrita. Apesar de a escola se propor a alfabetizar, ela o faz privilegiando uma modalidade da escrita: a alfabética. Essa escrita é parte fundamental do texto nossa cultura - mas não é o texto. Logo, o entendimento da escrita alfabética só acontecerá efetivamente se considerarmos os outros sistemas semióticos e suas possíveis conexões. É pelo entendimento da dinâmica cultural que avançaremos na ampliação do campo dos sentidos. Assim, a revisão do conceito de alfabetização é requisito básico para o desenvolvimento não só das escritas contemporâneoeletrônicas, como também para a escrita alfabética, ou seja, uma escrita em expansão (MACHADO, 1996).

Um dos pontos importantes na compreensão do conceito de alfabetização semiótica é entender o processo de culturalização. Como se viu, a cultura vem sofrendo modificações provenientes de processos sígnicos. Logo, é necessário compreender "o mundo como linguagem, que se manifesta em variadas formas de comunicação e em domínios igualmente diversificados" (MACHADO, 2003a, p. 26).

Na cultura, interagem diferentes sistemas de signos (literatura, religião, mito e folclore, cinema, etc.), que estão conjugados numa determinada hierarquia: um texto. Não seria uma acumulação desordenada de pequenos textos, mas, sim, um organismo complexo em que os códigos se encontram hierarquicamente organizados. Som, imagem, movimento, textura, cheiro, paladar não são meras extensões dos órgãos dos sentidos. São, pois, "elementos complexos resultantes de um processo semiótico, resultam da ação produtora de transformação de signos [...] os textos audiovisuais são exemplares nesse sentido, uma vez que seus exemplares são sistemas semióticos" (MACHADO, 2003b, p. 156).

Todo o texto da cultura é codificado por dois sistemas diferentes, pelo menos. Machado (2003a, p. 39) lembra que "os sistemas culturais são textos não porque se reduzem à língua, mas porque sua estruturalidade procede da modelização a partir da língua natural". 
A língua natural é um sistema modelizante primário. A partir dela, é possível entender outros sistemas da cultura: os sistemas modelizantes secundários. Logo, modelizar é construir sistemas de signos a partir de um modelo da língua natural. "Contudo, cada sistema desenvolve uma forma peculiar de linguagem e, no processo de descodificação do sistema modelizante não se volta para o modelo da língua, mas para o sistema que a partir dela foi construído" (MACHADO, 2003b, p. 50).

Nesse sentido, não podemos conceber os sistemas de cultura como isolados, independentes, acabados. Um texto da cultura só pode existir na sua relação com outros textos; um depende do outro para a sua organização. A alfabetização semiótica passa pelo entendimento dessa dinâmica, ou seja, de como os códigos estão conectados, enredados.

A capacidade de compreender os sistemas semióticos depende do conhecimento dos códigos culturais que fazem parte desses sistemas. Segundo Machado (2003b), a alfabetização semiótica torna-se necessária para o conhecimento dos códigos culturais. Como os códigos culturais não são sistemas isolados, conhecê-los e lê-los é uma tarefa difícil. É isso que a alfabetização semiótica se propõe a fazer: num primeiro momento, enxergar que a cultura é constituída pelo entrelaçamento de códigos e, num segundo, compreender os sistemas semióticos como produtos da culturalização.

Apesar de os cursos de Pedagogia propiciarem leituras de autores como Vigotski, Luria, Ferreiro, as concepções de linguagem presentes, na escola, ainda não possibilitam uma discussão que ajude a construção de uma alfabetização semiótica. Sabemos que esses autores apostam numa visão de homem que não só se constitui pela/na linguagem, mas, ao constituir-se, produz e modifica a linguagem: "O homem se apropria do mundo estudando a língua, decifrando o texto relativo e traduzindo-o em uma língua que lhe é acessível” (MACHADO, 2003b, p. 168). Somos seres culturais que nos apropriamos do mundo e o transformamos em texto. Como mecanismo que conjuga variados códigos, "capazes de transformar as mensagens recebidas e de gerar novas mensagens. Isso quer dizer que um texto não é um recipiente passivo de tudo o que vem do exterior" (MACHADO, 2003b, p. 169).

As linguagens não podem se esgotar no oral e no escrito, da mesma forma que o conceito de "texto" não se esgota no oral e na escrita. Tudo isso reforça a ideia de que a palavra escrita é parte da multiplicidade de linguagens que temos hoje. 
Portanto, o conceito de alfabetização amplia-se, porque lemos não só as palavras, como também as imagens, os sons que, muitas vezes, acompanham as imagens, enfim as diferentes linguagens.

Apesar de os conceitos de leitura terem mudado, nesses últimos tempos, o ato de ler permanece ainda mais vinculado à palavra escrita. Quando pensamos num "bom" leitor, consideramos a sua capacidade de ler textos verbais. Ler é mais do que isso, é um "processo de compreensão de expressões formais e simbólicas, não importando por meio de que linguagem" (MARTINS, 1996, p. 30). Assim, o ato de ler se refere tanto a algo escrito quanto a outros tipos de expressão do fazer humano, caracterizando-se como acontecimento histórico e estabelecendo uma relação, igualmente histórica, entre o leitor e o que é lido. Esse trabalho envolve tanto o conhecimento prévio dos signos e seu funcionamento quanto o conhecimento do leitor sobre o assunto abordado no texto.

Pensar em um único conceito de alfabetização, adequado a qualquer pessoa, em qualquer lugar, em qualquer momento é impossível. Dependendo das crenças, dos valores, do contexto social, teremos diferentes conceitos. Assim, a definição do que é ser alfabetizado depende das necessidades e condições sociais presentes em determinado momento histórico de uma sociedade e cultura. Além disso, em cada espaço social, as práticas de leitura e escrita são diferentes, ou seja, dependendo dos papéis sociais assumidos pelas pessoas, teremos demandas funcionais de leitura e escrita muito diferentes. Logo, torna-se difícil definir um único conjunto de habilidades e conhecimentos que constitua o que é ser alfabetizado hoje (SOARES, 2003).

\section{Considerações finais}

Não temos a pretensão de apresentar aqui uma conclusão com medidas e receitas a serem aplicadas. Apenas apontamos preocupações que precisam ser levantadas e discutidas no contexto escolar e de formação docente, em especial nos cursos de Pedagogia e Letras, tendo em vista a necessidade de conscientização da importância de se compreender os diferentes sistemas semióticos como fator determinante na formação e prática do professor da Educação Básica.

Partimos da ideia de que o entendimento de como a cultura hipermidiática vem se constituindo só é possível com sensibilização, reflexão e conhecimento sistematizado: alguém tem de mediar. Contudo, o que se observa é o fato do pouco 
tempo para a sensibilização, a reflexão e para a construção do conhecimento. Temos, sim, um trabalho escolar marcado pelo acúmulo de informação descontextualizada/ fragmentada e pela ausência de reflexão acerca dos processos culturais. Nesse sentido, o processo de alfabetização semiótica fica comprometido.

Numa perspectiva construtivista de ensino e aprendizagem, será possível estruturar uma proposta de alfabetização semiótica: visualizar a expansão cultural é também perceber como o homem vem se constituindo; é entender como a cultura vem se expandindo. Nessa concepção, o ser humano é um construtor ativo, não sendo mero produto do meio ambiente nem tampouco um simples resultado de seus mecanismos de maturação/estruturas internas. O conhecimento/cultura é construído na interação, em que a ação do sujeito sobre o objeto é mediada pelo outro por meio da linguagem. Logo, não acumulamos conhecimento/cultura: nós o transformamos e essa transformação é o próprio processo de expansão.

A tecnologia, por si só, não permite avanços no campo do sentido. Na realidade, o que possibilita avanços nesse campo é a ação cultural do homem; é o que ele faz com as tecnologias, como as usa. Isso ficou claro tanto na história da animação como na da escrita. O uso que fazemos de nossos sistemas de representação, os cruzamentos que experienciamos, a preocupação com os elementos que compõem tais sistemas têm possibilitado avanços no campo dos sentidos.

A escola, como cumpridora do papel de formar leitores e produtores de textos terá de aprender a dialogar com as linguagens que circulam nas (e pelas) tecnologias. Esse diálogo passará por um trabalho que enfatize mais as linguagens do que o uso instrumental dos meios apenas para ilustrar os conteúdos de uma determinada disciplina.

Finalizando, reforçamos a importância do trabalho com as conexões entre os códigos, pois esse é um dos caminhos para avançar no campo dos sentidos/ no processo de alfabetização semiótica. Ao entender e trabalhar essas conexões, percebemos e usufruímos de modos diferentes de dizer, de escrever, de escutar... Enfim, de compreender o mundo e de - quem sabe! - resgatar a nossa liberdade.

\section{Abstract}

In this paper we discuss the expansion of the concept of literacy, considering the expansion of writing in the current cultural context. For this, we present 
initially some relevant aspects of the history of writing, seeking to highlight the different systems of representation constructed by man. Next, we discuss the concept of literacy from the perspective of alphabetic writing, still widely applied in the guidelines and practices of teaching and learning of written language. To conclude, we discuss the contemporary writing and its influences on the culture and thinking of today's society and the concept of semiotic literacy.

Keywords: Literacy semiotics. Communication processes. Contemporary writings.

\section{Referências}

CAGLIARI, Luiz Carlos. Alfabetização \& linguística. São Paulo: Scipione, 1990.

DIRINGER, David. A escrita. São Paulo: Verbo,1985.

FERREIRO, Emilia. Reflexões sobre alfabetização. São Paulo: Cortez, 2001.

FLUSSER, Vilém. Pós-história: Vinte instantâneos e um modo de usar. São Paulo: Duas Cidades, 1983.

FLUSSER, Vilém. Filosofia da caixa preta - Ensaios para uma futura filosofia da fotografia. Rio de Janeiro: Relume Dumará, 2002.

GEERTZ, Clifford. A interpretação das culturas. Rio de janeiro: Livros Técnicos e Científicos, 1989.

HAVELOCK, Eric A. A revolução da escrita na Grécia e suas conseqüências culturais Tradução de Ordep José Serra. São Paulo: Editora UNESP; Paz e Terra, 1994.

HIGOUNET, Charles. História concisa da escrita. São Paulo: Parábola, 2003.

LURIA, Alexander R. Pensamento e linguagem. Tradução de Sérgio Spritzer. Porto Alegre: Artes Médicas, 1986.

MACHADO, Irene A. Alíngua entre as linguagens: Expansão da escrita no confronto de múltiplas escrituras. In: ENCONTRO NACIONAL DE PROFESSORES DE PORTUGUÊS DAS ETF'S, EAF'S E CEFET'S, 11, Anais..., Natal: MEC, 1996.

MACHADO, Irene A. Semiótica como teoria da comunicação. In: WEBER, Maria Helena; BENTZ, Ione Maria Ghislene; HOHLFELDT, Antonio. Tensões e objetos da pesquisa em comunicação. Porto Alegre: Sulinas, 2002. 
MACHADO, Irene A. As mídias e seus precursores: emergência das mediações como campo de idéias científicas. Significação. São Paulo: Anablume, 2003a.

MACHADO, Irene A. Escola de semiótica - A experiência de Tártu-Moscou para o estudo da cultura. São Paulo: Ateliê Editorial, 2003b.

MANGUEL, Alberto. Lendo imagens. São Paulo: Companhia das Letras, 2002.

MARTINS, Maria Helena. O que é leitura. São Paulo: Brasiliense, 1996.

MCLUHAN, Marshall. Os meios de comunicação como extensões do homem. Tradução de Décio Pignatari. São Paulo: Pensamento; Cultrix, 2002.

MCLUHAN, Marshall. A galáxia de Gutenberg. Tradução de Leônidas Gontijo de Carvalho e Anísio Teixeira. São Paulo: Nacional, 1977.

MCLUHAN, Marshall. Revolução na comunicação. In: Aulas sem paredes. Tradução de Álvaro Cabral. Rio de Janeiro: Zahar Editores, 1968.

ONG, Walter. Oralidade e cultura escrita. Tradução de Enid Abreu Dobránszky. Campinas, SP: Papirus, 1998.

ROCCO, Maria Thereza Fraga. Entre a oralidade e a escrita: reflexões esparsas. In: Espaços da linguagem. São Paulo: Humanitas, 1999.

SARAMAGO, José. A jangada de pedra. Rio de Janeiro: Record, 1980.

SOARES, Magda Becker. Alfabetização e letramento. São Paulo: Contexto, 2003.

TEIXEIRA, Anísio. O pensamento precursor de McLuhan. Revista Brasileira de estudos pedagógicos, Brasília, v. 54, n. 119, jul./set. 1970.

VIGOTSKI, Lev Semenovich. A formação social da mente. Tradução de José Cipolla Neto, Luis Silvério Menna Barreto e Solange Castro Afeche. São Paulo: Martins Fontes, 1994.

VILCHES, Lorenzo. A migração digital. Tradução de Maria Imacolata Vassallo de Lopes. São Paulo: Loyola, 2003.

Submetido em: 06 de outubro de 2015. Aceito para publicação em: 15 de outubro de 2015. 
